\title{
Adsorption from Aqueous Solution Onto Natural and Acid Activated Bentonite
}

\author{
${ }^{1}$ Laila Al-Khatib, ${ }^{2}$ Feras Fraige, \\ ${ }^{1}$ Mohammad Al-Hwaiti and ${ }^{1}$ Omar Al-Khashman \\ ${ }^{1}$ Department of Environmental Engineering, \\ ${ }^{2}$ Department of Mining Engineering, \\ Faculty of Engineering, Al-Hussein Bin Talal University, Ma'an 71111, P O Box 25, Jordan
}

Received 2012-07-03, Revised 2012-08-14; Accepted 2012-08-17

\begin{abstract}
Dyes have long been used in dyeing, paper and pulp, textiles, plastics, leather, paint, cosmetics and food industries. Nowadays, more than 100,000 commercial dyes are available with a total production of 700,000 tones manufactured all over the world annually. About $10-15 \%$ of dyes are being disposed off as a waste into the environment after dyeing process. This poses certain hazards and environmental problems. The objective of this study is to investigate the adsorption behavior of Methylene Blue (MB) from aqueous solution onto natural and acid activated Jordanian bentonite. Both bentonites are firstly characterized using XRD, FTIR and SEM techniques. Then batch adsorption experiments were conducted to investigate the effect of initial MB concentration, contact time, $\mathrm{pH}$ and temperature. It was found that the percentage of dye removal was improved from $75.8 \%$ for natural bentonite to reach $99.6 \%$ for acid treated bentonite. The rate of MB removal followed the pseudo second order model with a high correlation factor. The Langmuir and Freundlich adsorption models were applied to describe the equilibrium isotherms. The Langmuir isotherm model was found more representative. The results indicate that bentonite could be employed as a low cost adsorbent in wastewater treatment for the removal of colour and dyes.
\end{abstract}

Keywords: Adsorption, Bentonite, Methylene Blue, Acid Activation

\section{INTRODUCTION}

Dyes have long been used in dyeing, paper and pulp, textiles, plastics, leather, paint, cosmetics and food industries (Chen and Zhao, 2009; Gupta and Suhas, 2009). Nowadays, more than 100,000 commercial dyes are available with a total production of 700,000 tones manufactured all over the world annually. About 10-15\% of dyes are being disposed off as a waste into the environment after the completion of dying process (Gupta and Suhas, 2009). Coloured stuff discharged from these industries poses certain hazards and environmental problems. These compounds are not only aesthetically displeasing but also dyes interfere with the transmission of light and upset the biological metabolism processes which cause the destruction of aquatic communities present in ecosystem (Ozcan and Ozcan, 2004). In addition, dyes usually have complex aromatic molecular structures which make them more stable and difficult to biodegrade. Furthermore, many dyes are toxic to some microorganisms and may cause direct destruction or inhibition of their catalytic capabilities (Srinivasan and Viraraghavan, 2010).

Dyes also affect human and animal health. For example, when they come into contact with eyes, they result in eye burns and could lead to permanent injury to human or animals. In addition, inhalation of some dyes could result in rapid or difficult breathing. While ingestion through the mouth produces a burning sensation and may cause nausea, vomiting, profuse sweating, mental confusion and methemoglobinemia (Hameed et al., 2001). In addition dyes can cause

Corresponding Author: Laila Al-Khatib, Department of Environmental Engineering, Faculty of Engineering, Al-Hussein Bin Talal University, Ma'an 71111, P O Box 25, Jordan 
allergic dermatitis, skin irritation, cancer and mutations (Gupta and Suhas, 2009).

Hence treating wastewater with dyes is of a prime importance. There are several methods for dye removals, such as adsorption, oxidation-ozonation, coagulation, coagulation-flocculation and biological methods (Eren and Afsin, 2009; Turabik, 2008; Waranusantigul et al., 2003; Juang et al., 1997).

Adsorption process provides an attractive treatment of wastewater containing dyes over other conventional wastewater treatment techniques due to economic consideration, its availability and easy to operate as well as greater efficiency (Eren and Afsin, 2009; Gok et al., 2010). Activated carbon is widely used as an adsorbent in gas and liquid phase separation. However, the activated carbon remains an expensive material. This depresses its large scale usage. In order to overcome this deficiency, many researchers investigated the development and preparation of low cost alternative adsorbents such as wood (Poots et al., 1978), dead and pretreated (A. niger) fungus (Fu and Viraraghavan, 2000; 2001a; 2001b; 2002a; 2002b), zeolite (Armagan et al., 2004; Wang et al., 2006), Tripoli (ALzaydien, 2009) and bentonite (Ozcan and Ozcan, 2004; Hu et al., 2006).

In the present study, the adsorption of Methylene Blue (MB) dye onto two adsorbents; natural and acid activated bentonite were studied. Various parameters affecting adsorption process, such as contact time, initial dye concentration, temperature and $\mathrm{pH}$ were investigated. In addition, kinetic parameters were also calculated to determine adsorption mechanism and rate constants. Experimental data at equilibrium was fitted into adsorption isotherms in order to give the best fit correlation.

\section{MATERIALS AND METHODS}

\subsection{Bentonite}

The bentonite used in this study was supplied by Jordanian Natural Resources Authority (NRA) from AlAzraq Basin, northeastern Jordan. Clay sample was crushed, ground and sieved. The bentonite sample was stored in an air-tight container for further use.

\subsection{Preparation of Acid-Activated Bentonite}

For acid-activation bentonite, sample of $100 \mathrm{~g}$ of natural bentonite was soaked in $500 \mathrm{~mL}$ of $5 \mathrm{M} \mathrm{HCl}$ acid for $24 \mathrm{~h}$. at room temperature. The activated bentonite was washed several times with distilled water until the $\mathrm{pH}$ of the solution was 6 . Then it was dried at $105^{\circ} \mathrm{C}$ until constant mass and grounded to pass $106 \mu \mathrm{m}$. It is then stored for further use.

\subsection{Adsorbate}

The Adsorbate used in this study is the basic dye, Methylene Blue (MB). It was purchased from SigmaAldrich (molecular weight $319.87 \mathrm{~g} \mathrm{moL}^{-1}$ ) and used without further purification. Different concentrations of MB were prepared from a stock of $1000 \mathrm{ppm}$ solution with distilled water. To determine the dye concentration, a calibration curve was first obtained from a series of predetermined concentration of dye solutions. The maximum absorbance of the dye was confirmed by scanning the dye aqueous solution over the spectral range of 550-660 $\mathrm{nm}$ by using UV-vis spectrophotometer (Model SPUV-19). The absorbance of those standard samples was then measured at the corresponding maximum wavelength. Absorbance of dye solution after adsorption experiment was then converted to concentration using the established calibration curve.

\subsection{Adsorbents Characterization}

The mineralogical composition of bentonite samples was determined using X-ray Diffraction (XRD) technique. X-ray analyses of the samples were made using (Shimadzu model XRD6000). The FTIR spectra of both natural and acid activated bentonite were obtained with $\mathrm{KBr}$ using Shimadzu model R-prestige Fourier Transform Infrared Spectrometer to observe the surface functional groups. FTIR spectra were recorded in the region of $4000-400 \mathrm{~cm}^{-1}$. The Scanning Electron Microscopy (SEM) analysis was carried out using a FEI Scanning Electron Microscope (Inspect F 50) equipped with a Silicon-drifted Energy Dispersive X-ray spectrometer (SEM-EDX). Operating conditions were $5 \mathrm{kV}$ accelerating voltage at full vacuum.

\subsection{Batch Adsorption Study}

Adsorption experiments were carried out batch wise. A specific amount of adsorbent was added to dark amber glass bottles of $100 \mathrm{~mL}$ capacity containing $50 \mathrm{~mL}$ of MB solution of desired concentrations in the range 10 to $100 \mathrm{mg} \mathrm{L}^{-1}$. The bottles were subsequently capped and placed on a controlled temperature mechanical shaker at a speed of $250 \mathrm{rpm}$ at desired temperature and time. After adsorption, the solution was centrifuged at 3000 rpm for $6 \mathrm{~min}$. The residual dye concentrations of each solution were determined by measuring their characteristic absorbance using a single beam UV-Vis spectrophotometer (Model SPUV-19) at a wavelength of maximum absorbance $(660 \mathrm{~nm})$. The absorbance is then converted to concentration using the calibration curve.

The amount of adsorbed MB at any time, $\mathrm{q}_{\mathrm{t}}(\mathrm{mg} / \mathrm{g})$, was calculated using Eq. 1: 
$\mathrm{q}_{\mathrm{t}}=\frac{\left(\mathrm{C}_{0}-\mathrm{C}_{\mathrm{t}}\right) \mathrm{V}}{\mathrm{m}}$

where, $\mathrm{C}_{0}$ and $\mathrm{C}_{\mathrm{t}}$ are the initial and liquid-phase concentrations at any time $\mathrm{t}$ of dye solution $(\mathrm{mg} / \mathrm{L})$, respectively, $\mathrm{V}$ is the volume of dye solution (L) and $\mathrm{m}$ is the mass $(\mathrm{g})$ of the adsorbent used.

The removal efficiency, $\mathrm{R}(\%)$ of the system, is Eq. 2:

$$
\mathrm{R}=\frac{\mathrm{C}_{0}-\mathrm{C}_{\mathrm{t}}}{\mathrm{C}_{0}} \times 100
$$

\subsection{Effect of Adsorption Parameters}

To examine the effect of temperature, adsorption experiments were conducted at 25,35 and $45^{\circ} \mathrm{C}$, respectively. The influence of the initial $\mathrm{pH}$ was studied at values: 3, 5, 7 and 9. Dye solution $\mathrm{pH}$ was adjusted using $0.1 \mathrm{M} \mathrm{NaOH}$ and $0.1 \mathrm{M} \mathrm{HCl}$ solutions and measured using a Meter Lab, pH M210 meter. Adsorbent dosage used in this study was in the range 2 to $60 \mathrm{~g} \mathrm{~L}^{-1}$.

\section{RESULTS}

\subsection{Characterization of the Adsorbents}

Bentonite is considered one of the most promising natural materials available in Jordan that can be used for adsorption of some dyes found in wastewater. The chemical composition of natural bentonite is (in \%): $\mathrm{SiO}_{2}$ : 43.32, $\mathrm{Al}_{2} \mathrm{O}_{3}: 12.59, \mathrm{~K}_{2} \mathrm{O}: 2.89, \mathrm{CaO}: 9.59, \mathrm{MgO}$ : 4.99, $\mathrm{Fe}_{2} \mathrm{O}_{3}: 5.95, \mathrm{TiO}_{2}: 0.59, \mathrm{Na}_{2} \mathrm{O}: 2.25$ and loss of ignition: 17.41 (Khoury, 2002). This indicates the presence of silica, alumina, calcium oxide, iron oxide and magnesium oxide as major constituents. Traces of sodium, potassium and titanium oxides are found in the form of impurities.

The ratio $\mathrm{SiO}_{2} / \mathrm{Al}_{2} \mathrm{O}_{3}$ is 3.44 which indicate that the bentonite is of montmorillonite nature. This is also confirmed by the XRD analysis. The mineral phases identified along with montmorillonite were quartz and minor levels of feldspar, dolomite and calcite.

In order to illustrate the effect of acid activation of bentonite, FTIR and SEM have been conducted. The FTIR spectra of natural bentonite and acid activated bentonite were taken in the range of $4000-400 \mathrm{~cm}^{-1}$. FTIR spectroscopy is very sensitive to modification of the clay structure upon acid treatment as illustrated in Fig. 1. In FTIR-spectrum of the acid activated bentonite, weakening of absorption band intensity at 3426 and 1639 $\mathrm{cm}^{-1}$ is marked (Fig. 1b). It corresponds to the process of removal of interlayer water (Farmer, 1971; 1974; Wilson, 1994; Olphen, 1977; Hideomi, 1977; Loeb and
Schrader, 1992). Absorption peaks between 3426 and $3626 \mathrm{~cm}^{-1}$ are due to stretching bands of the $\mathrm{OH}$ groups. While the band at $1639 \mathrm{~cm}^{-1}$ corresponds to the $\mathrm{OH}$ deformation of water to observe natural bentonite and acidactivated bentonite, but the peak intensities of acid-activated bentonite are lower than that of natural bentonite. Absorption band reduction at $3626 \mathrm{~cm}^{-1}$ indicates development of dehydroxylation process. This is believed to occur as a result of acid activation of bentonite (Ozcan and Ozcan, 2004; Vlasova et al., 2003).

In addition, the transformation of the tetrahedral sheet was found at $781 \mathrm{~cm}^{-1}$. The acid activation leads to the formation of amorphous silica, indicated by the increased intensity of the peak, which may expose more adsorption sites (Komandel et al., 1990).

Natural and acid activated bentonite samples were analyzed to detect the change in surface morphology after acid activation using SEM. Clumps of uneven surface can be seen for acid activated bentonite with distribution of pores (Fig. 2b) compared with flat flakes of low porosity for natural bentonite (Fig. 2a). The leaching of cations by acid activation creates voids in the bentonite leading to increase its surface porosity.

\subsection{Effect of Contact Time and Initial (MB) Concentration on Adsorption}

The effect of contact time on the percentage of color removal using various initial dye concentrations range from 10 to $100 \mathrm{mg} \mathrm{L}^{-1}$ was examined at different time as shown in Fig. 3. The results showed that the rate of adsorbed MB onto both natural and acid activatedbentonite was initially rapid and then it slowed down gradually until equilibrium was attained.

As Fig. 3 illustrates, uptake attained equilibrium at 60 min for acid activated bentonite while it needed $180 \mathrm{~min}$ using natural bentonite at the same conditions.

The results also indicated that the amount of retained dye increased with the increase of initial dye concentration. Although the rate behavior of both bentonite and acid activated bentonite was similar, but it has been found that under identical conditions the acid activated bentonite presented higher adsorption capacity.

\subsection{Effect of pH on Adsorption}

The effect of $\mathrm{pH}$ on $\mathrm{MB}$ adsorption onto natural and acid activated bentonite was studied through tests carried out on solutions of various $\mathrm{pH}$ as shown in Fig. 4. It showed that the adsorption of $\mathrm{MB}$ dye onto natural bentonite increased with increasing solution $\mathrm{pH}$.

However, the adsorption of MB dye on acid activated bentonite was controlled by a $\mathrm{pH}$-independent adsorption mechanism as indicated in Fig. 4. 


\subsection{Effect of Temperature}

The effect of temperature on the equilibrium adsorption capacity of MB onto both bentonite and acid activated bentonite was investigated at a concentration of $100 \mathrm{mg} \mathrm{L}^{-1}$ at 25,35 and $45^{\circ} \mathrm{C}$. The results were presented in Fig. 5. It can be seen that with the increase of temperature, the adsorption capacity of $\mathrm{MB}$ onto natural bentonite was slightly increased (about 3\%). This observation revealed that the adsorption process is slightly endothermic.

On the other hand, the adsorption capacity of MB onto acid activated bentonite has a negligible effect, suggesting the adsorption behavior was insensitive to the changes of temperature in the range investigated.

\subsection{Effect of Adsorbent Dosage}

The effect of adsorbent concentration on the percentage removal of $\mathrm{MB}$ dye using an initial dye concentration of $100 \mathrm{ppm}$ is examined. The studied adsorbent dosages were 2, 10, 40 and $60 \mathrm{~g} \mathrm{~L}^{-1}$ as shown in Fig. 6. It can be noticed that increasing the natural bentonite dosage gradually increase the percentage removal of MB. It was also noted that increasing the dosage of acid activated bentonite from $2-10 \mathrm{~g} \mathrm{~L}^{-1}$ increase the percentage removal of MB dye.

However, when the dosage of acid- activated bentonite increased from 10 to $60 \mathrm{~g} \mathrm{~L}^{-1}$ the removal of MB was constant.

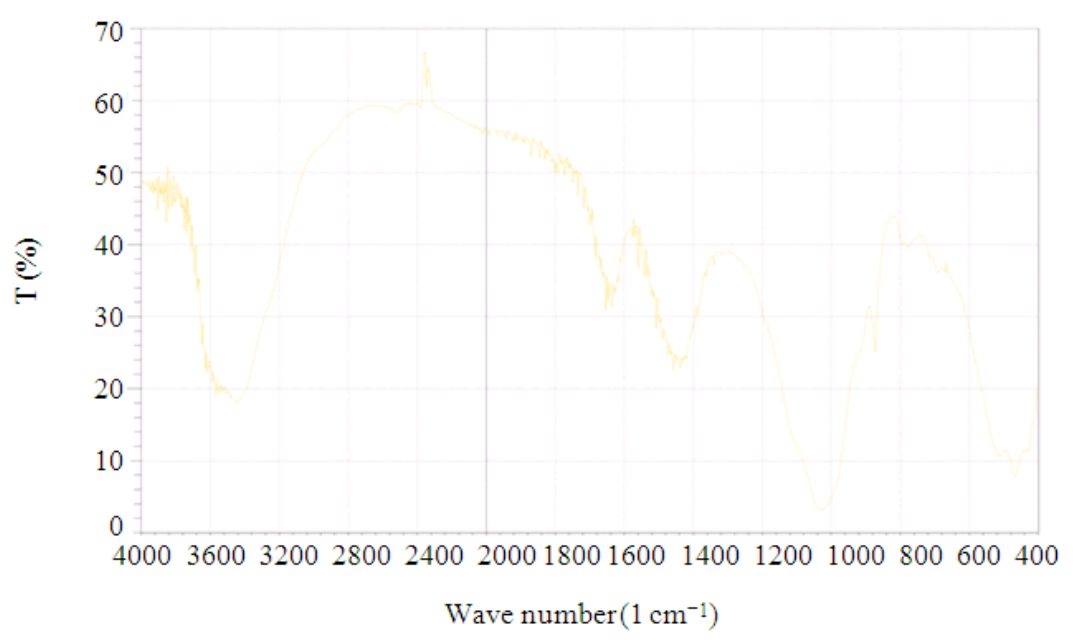

(a)

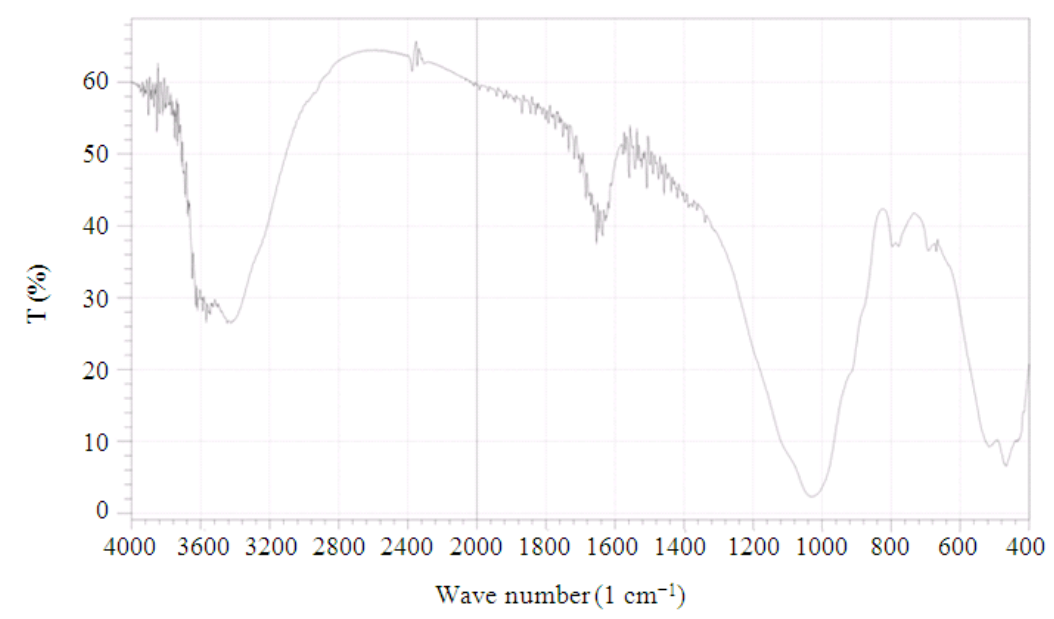

(b)

Fig. 1. FTIR spectra of natural bentonite (a) and acid-activated bentonite (b) 
Laila Al-Khatib et al. / American Journal of Environmental Science 8 (5) (2012) 510-522

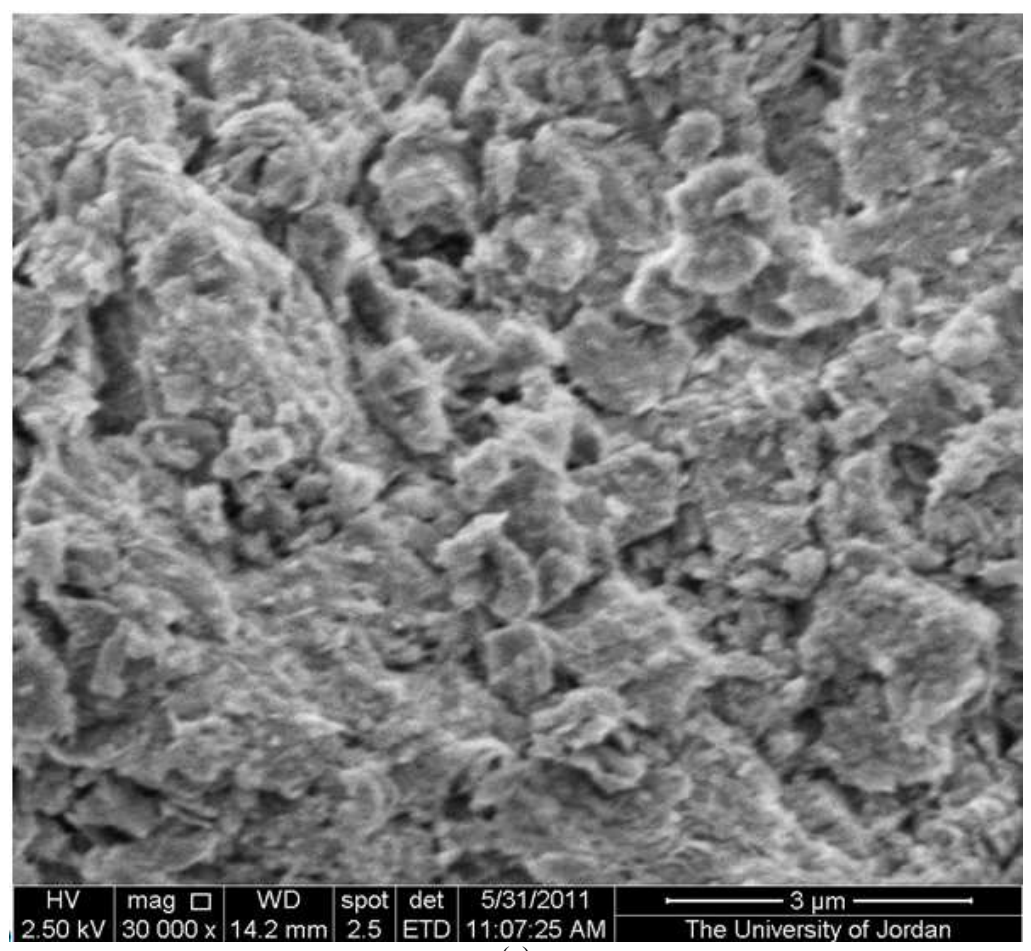

(a)

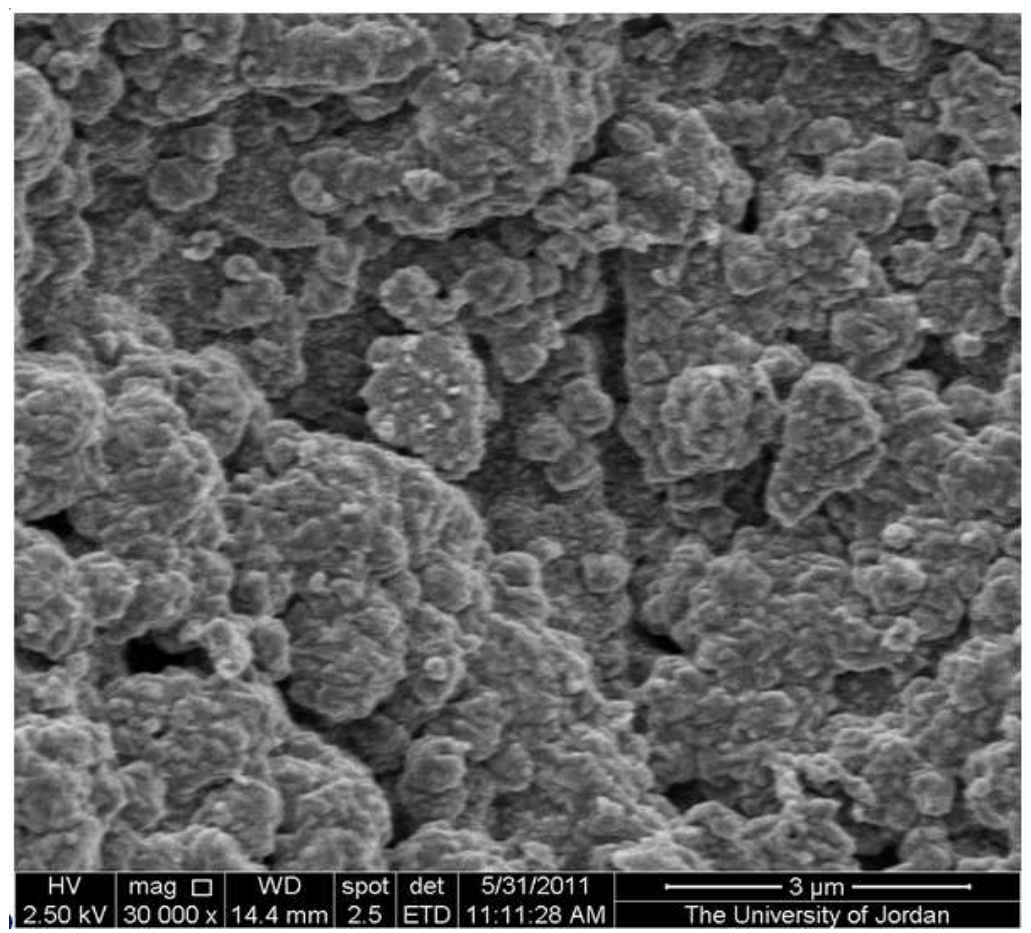

(b)

Fig. 2. SEM surface morphology of natural bentonite (a) and acid-activated bentonite (b) 
Laila Al-Khatib et al. / American Journal of Environmental Science 8 (5) (2012) 510-522

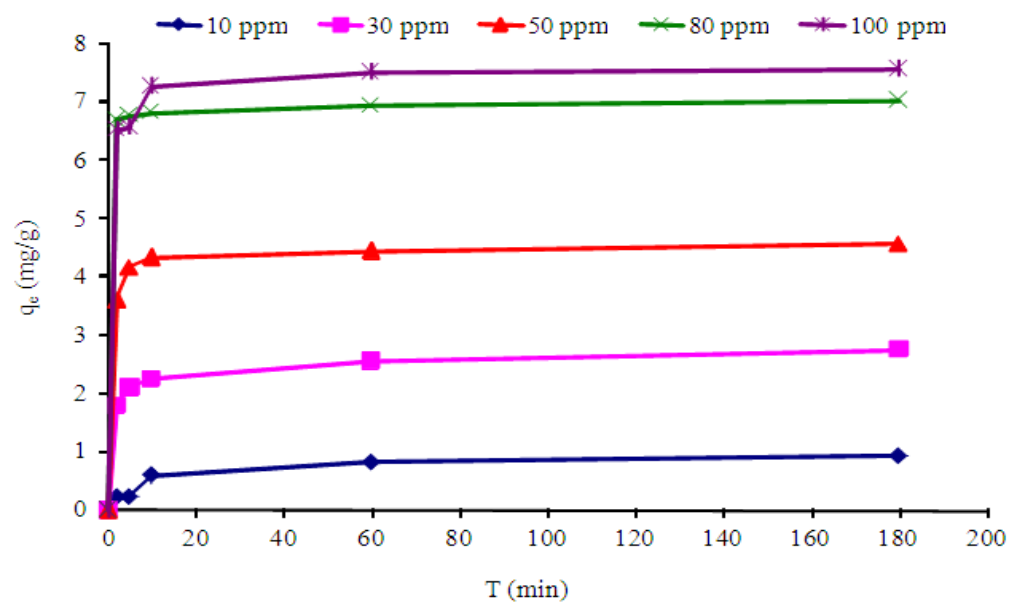

(a)

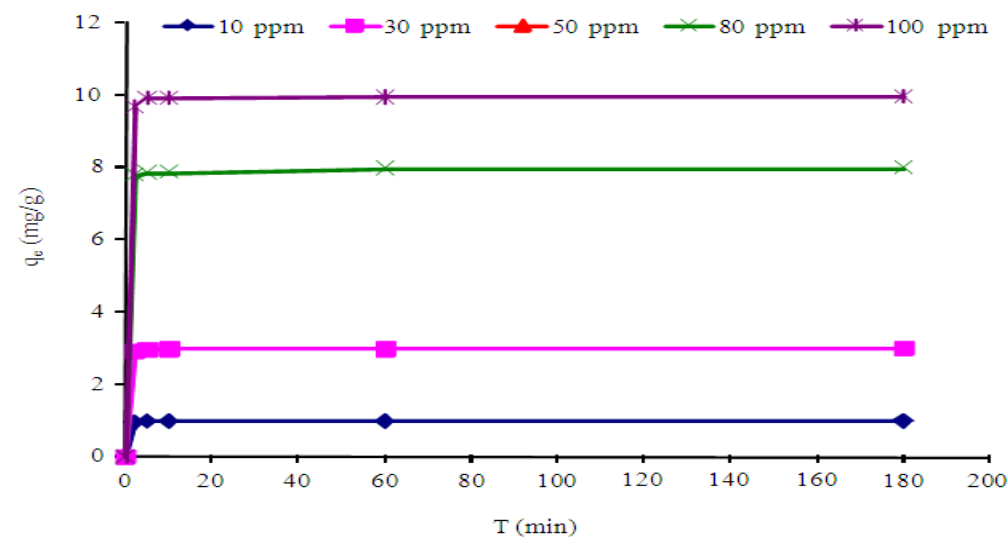

(b)

Fig. 3. Effect of contact time on $\mathrm{MB}$ adsorption on natural bentonite (a) and acid activated bentonite (b) at different initial concentrations (temperature $=20 \pm 2^{\circ} \mathrm{C}, \mathrm{pH}=9$, dosage $=10 \mathrm{~g} \mathrm{~L}^{-1}$ )

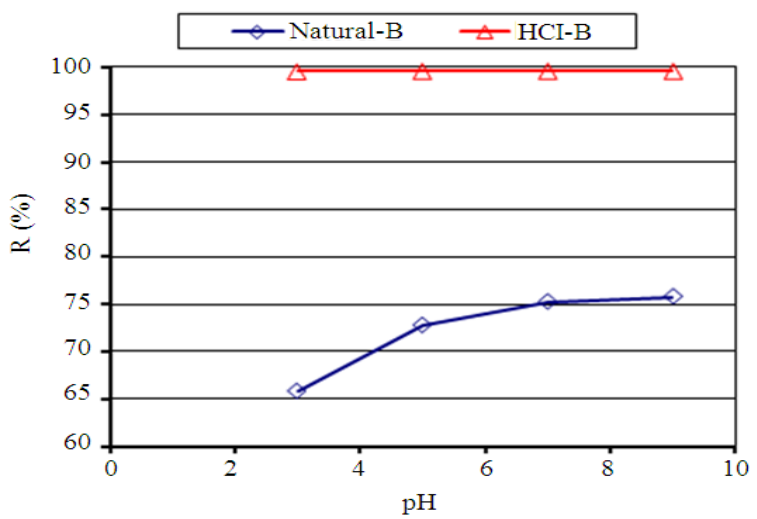

Fig. 4. Effect of $\mathrm{pH}$ on $\mathrm{MB}$ removal by natural bentonite (diamonds) and acid- activated bentonite (triangles) at initial concentration $=100 \mathrm{ppm}$, temperature $=20 \pm 2^{\circ} \mathrm{C}$ and dosage $=10 \mathrm{~g} \mathrm{~L}^{-1}$

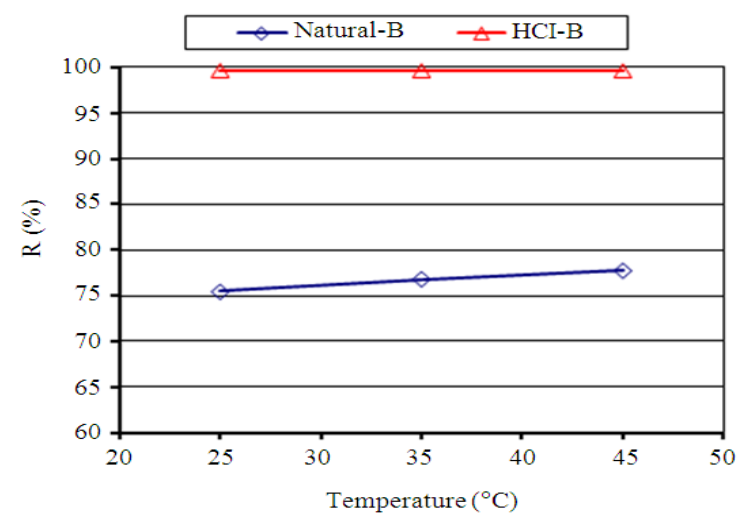

Fig. 5. Effect of temperature on MB removal by natural bentonite (diamonds) and acid- activated bentonite (triangles) at initial concentration $=100 \mathrm{ppm}, \mathrm{pH}=9$ and dosage $=10 \mathrm{~g} \mathrm{~L}^{-1}$ 
Laila Al-Khatib et al. / American Journal of Environmental Science 8 (5) (2012) 510-522

Table 1. Kinetic models' parameters for natural and acid-activated bentonite

\begin{tabular}{|c|c|c|c|c|c|c|c|c|c|c|c|c|}
\hline \multirow[b]{3}{*}{$\begin{array}{l}\mathrm{C}_{0} \\
(\mathrm{mg} / \mathrm{L})\end{array}$} & \multicolumn{6}{|c|}{ First order kinetic model parameters } & \multicolumn{6}{|c|}{ Second order kinetic model parameters } \\
\hline & \multicolumn{3}{|c|}{ Natural bentonite } & \multicolumn{3}{|c|}{ Acid-activated bentonite } & \multicolumn{3}{|c|}{ Natural bentonite } & \multicolumn{3}{|c|}{ Acid-activated bentonite } \\
\hline & $\begin{array}{l}\mathrm{q}_{\mathrm{e}} \\
(\mathrm{mg} / \mathrm{g})\end{array}$ & $\begin{array}{l}\mathrm{K}_{1} \\
\left(\min ^{-1}\right)\end{array}$ & $\mathrm{R}^{2}$ & $\begin{array}{l}\mathrm{q}_{\mathrm{e}} \\
(\mathrm{mg} / \mathrm{g})\end{array}$ & $\begin{array}{l}\mathrm{K}_{1} \\
\left(\mathrm{~min}^{-1}\right)\end{array}$ & $\mathrm{R}^{2}$ & $\begin{array}{l}\mathrm{q}_{\mathrm{e}} \\
(\mathrm{mg} / \mathrm{g})\end{array}$ & $\begin{array}{l}\mathrm{K}_{2} \\
(\mathrm{~g} / \mathrm{mg} \min )\end{array}$ & $\mathrm{R}^{2}$ & $\begin{array}{l}\mathrm{q}_{\mathrm{e}} \\
(\mathrm{mg} / \mathrm{g})\end{array}$ & $\begin{array}{l}\mathrm{K}_{2} \\
(\mathrm{~g} / \mathrm{mg} \min )\end{array}$ & $\mathrm{R}^{2}$ \\
\hline 10 & 1.14 & 0.031 & 0.670 & 0.07 & 0.034 & 0.220 & 0.94 & 0.174 & 0.999 & 1.00 & 5.258 & 1 \\
\hline 30 & 0.74 & 0.033 & 0.910 & 0.13 & 0.052 & 0.314 & 2.76 & 0.221 & 1.000 & 2.99 & 6.052 & 1 \\
\hline 50 & 1.00 & 0.039 & 0.488 & 0.76 & 0.470 & 0.594 & 4.57 & 0.392 & 1.000 & 4.99 & 0.359 & 1 \\
\hline 80 & 0.75 & 0.040 & 0.368 & 0.54 & 0.061 & 0.474 & 7.03 & 0.622 & 1.000 & 7.98 & 1.764 & 1 \\
\hline 100 & 1.70 & 0.061 & 0.718 & 0.33 & 0.067 & 0.718 & 7.58 & 0.392 & 1.000 & 9.96 & 3.600 & 1 \\
\hline
\end{tabular}

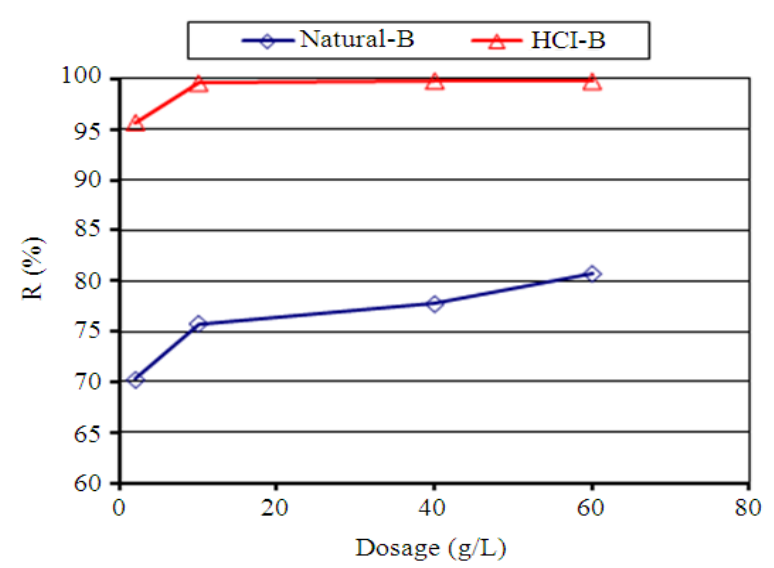

Fig. 6. Effect of dosage on MB removal by natural bentonite (diamonds) and acid- activated bentonite (triangles) at initial concentration $=100 \mathrm{ppm}$ and temperature $=20$ $\pm 2^{\circ} \mathrm{C}, \mathrm{pH}=9$

\subsection{Adsorption Kinetics}

In order to examine the adsorption kinetics, two popular kinetic models: pseudo-first order and pseudosecond order were applied. The linear forms of these models can be expressed as follows Eq. 3 and 4 (Lagergren, 1898; Ho and McKay, 1998):

$\ln \left(\mathrm{q}_{\mathrm{e}}-\mathrm{q}_{\mathrm{t}}\right)=\ln \mathrm{q}_{\mathrm{e}}-\mathrm{k}_{1} \mathrm{t}$

$\frac{\mathrm{t}}{\mathrm{q}_{\mathrm{t}}}=\frac{1}{\mathrm{k}_{2} \mathrm{q}_{\mathrm{e}}{ }^{2}}+\frac{1}{\mathrm{q}_{\mathrm{e}}} \mathrm{t}$

where, $\mathrm{q}_{\mathrm{e}}$ and $\mathrm{q}_{\mathrm{t}}$ are the amount of dye adsorbed on adsorbent at equilibrium and time $\mathrm{t}$, respectively $(\mathrm{mg} / \mathrm{g})$ and $\mathrm{k}_{1}$ is the rate constant of first order adsorption $\left(\mathrm{min}^{-1}\right) . \mathrm{k}_{2}$ is the pseudo-second order rate constant of adsorption $\left(\mathrm{g} \mathrm{mg}^{-1} \mathrm{~min}^{-1}\right)$.

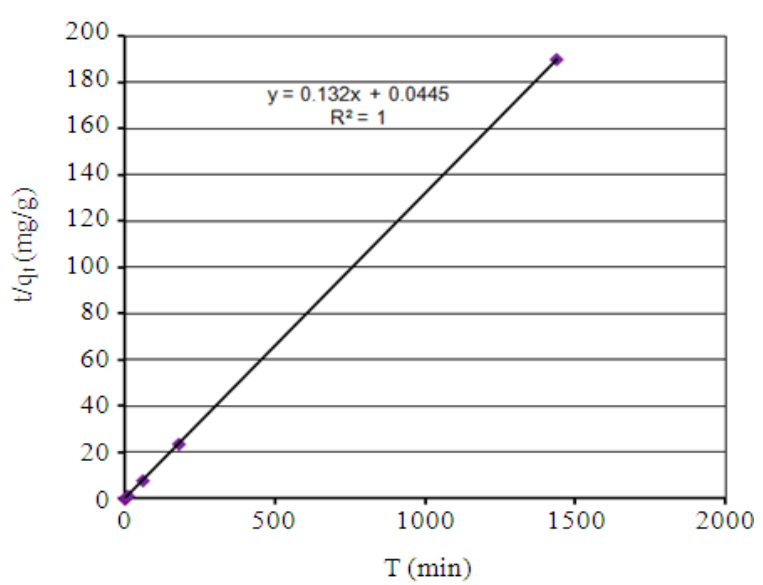

(A)

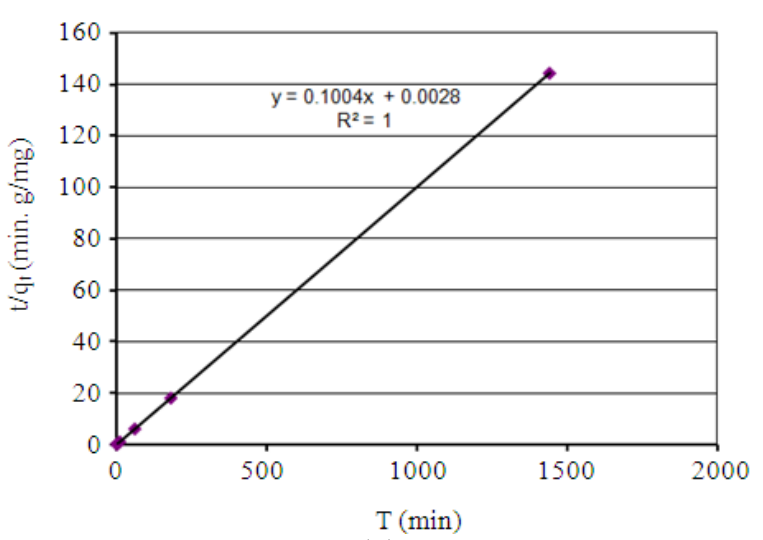

(B)

Fig. 7. Pseudo-second order adsorption kinetic model for MB adsorbed on natural bentonite (A) and acid-activated bentonite (B) (initial concentration $=100 \mathrm{ppm}$, temperature $=20 \pm 2^{\circ} \mathrm{C}, \mathrm{pH}=9$ and dosage $=10 \mathrm{~g} \mathrm{~L}^{-1}$ )

The parameters $\mathrm{q}_{\mathrm{e}}$ and $\mathrm{k}_{1}$ obtained from pseudo-first order adsorption kinetic model were calculated and summarized in Table 1. The regression correlation 
factors were generally low; therefore, the adsorption kinetics of $\mathrm{MB}$ dye on natural and acid activated bentonite did not show good compliance with pseudofirst order adsorption kinetic model.

Further investigation has been carried out to gauge the compliance of the adsorption kinetics with the pseudo-second order kinetic model. Figure 7 shows the application of the pseudo-second order kinetic model for the adsorption systems of both adsorbents and for initial dye concentration $=100 \mathrm{ppm}$. The regression coefficients obtained are almost 1 , which indicates a good compliance of this model with experimental data.

With increasing initial dye concentration from 10 to $100 \mathrm{mg} \mathrm{L}^{-1}$, the adsorption capacity increases from 0.94 to $7.58 \mathrm{mg} \mathrm{g}^{-1}$ and from 1.0 to $9.96 \mathrm{mg} \mathrm{g}^{-1}$ for natural and acid activated bentonite, respectively as summarized in Table 1. This indicates that dye removal content depends on the initial dye concentration when the adsorbent amount is constant.

\subsection{Adsorption Isotherms}

Adsorption isotherm models are very useful for predicting adsorption capacities and also for incorporating into mass transfer relationships in the design of contacting equipment. So, in order to optimize the design of an adsorption system to remove MB dye from effluents, it is important to establish the most appropriate correlation for the equilibrium curves. In this respect, the equilibrium experimental data for adsorbed MB onto natural and acid activated bentonite were compared using two isotherm models: Langmuir and Freundlich.

\subsection{Langmuir Isotherm Model}

The Langmuir adsorption model depends on the assumption that the intermolecular forces decrease rapidly with distance and consequently predicts the existence of monolayer coverage of the adsorbate at the outer surface of the adsorbent (Langmuir, 1918). In addition, the isotherm model assumes that adsorption occurs at specific homogeneous sites within the adsorbent. It is assumed that once a dye molecule occupies a site, no further adsorption can take place at that site. Furthermore, the Langmuir equation is based on the assumption of a structurally homogeneous adsorbent, where all sorption sites are identical and energetically equivalent.

Theoretically, the sorbent has a finite capacity for the sorbate. Therefore, a saturation value is reached beyond which no further sorption can occur. The saturated or monolayer capacity can be represented as the known Langmuir (1918) Eq. 5:

$$
\frac{1}{\mathrm{q}_{\mathrm{e}}}=\frac{1}{\mathrm{q}_{\max }}+\left(\frac{1}{\mathrm{q}_{\max } \mathrm{K}_{\mathrm{L}}}\right) \frac{1}{\mathrm{C}_{\mathrm{e}}}
$$

where, $\mathrm{q}_{\max }(\mathrm{mg} / \mathrm{g})$ and $\mathrm{K}_{\mathrm{L}}(\mathrm{L} / \mathrm{mg})$ are the Langmuir constants and $\mathrm{C}_{\mathrm{e}}(\mathrm{mg} / \mathrm{L})$ is the equilibrium dye concentration in the solution.

The Langmuir adsorption equilibrium isotherm of MB dye onto both clays at $20^{\circ} \mathrm{C}$ is presented in Fig. 8 . Regression analysis reveals that the Langmuir model fits the experimental data well with correlation factor higher than 0.98 for both adsorbents.

An essential characteristic of Langmuir isotherm can be expressed by a dimensionless constant called separation factor, $\mathrm{R}_{\mathrm{L}}$ (Hall et al., 1966) given by:

$$
\mathrm{R}_{\mathrm{L}}=\frac{1}{1+\mathrm{K}_{\mathrm{L}} \mathrm{C}_{\mathrm{m}}}
$$

where, $\mathrm{C}_{\mathrm{m}}$ is the highest initial dye concentration (here $100 \mathrm{ppm}$ ). The value of $R_{\mathrm{L}}$ indicates the type of the isotherm to be either unfavorable when $R_{L}>1$, linear if $R_{L}$ $=1$, favourable if $0<R_{L}<1$ or irreversible when $R_{L}=0$.

The $R_{L}$ values are 0.056 for natural bentonite and 0.005 for acid activated bentonite as shown in Table 2 indicating that the adsorption of this dye on both adsorbents was a favorable process.

\subsection{Freundlich Isotherm Model}

This model describes heterogeneous adsorption systems (Freundlich, 1906). The model is given in its linear form as Eq. 6:

$$
\operatorname{lnq}_{\mathrm{e}}=\ln \mathrm{K}_{\mathrm{F}}+\frac{1}{\mathrm{n}} \ln \mathrm{C}_{\mathrm{e}}
$$

where, $\mathrm{K}_{\mathrm{F}}$ is the Freundlich constant related to overall adsorption capacity $(\mathrm{mg} / \mathrm{g})$; and $1 / \mathrm{n}$ is a dimensionless constant related to the intensity of adsorption, or the heterogeneity factor describes reversible adsorption and is not restricted to the formation of the monolayer.

Figure 9 shows plots of $\ln \mathrm{q}_{\mathrm{e}}$ versus $\ln \mathrm{C}_{\mathrm{e}}$ for the adsorption of $\mathrm{MB}$ dye on natural and acid activated bentonite. Values of $\mathrm{K}_{\mathrm{F}}$ and $\mathrm{n}$ are obtained from intercept and slope, respectively. These are 1.54 and 1.7 for natural bentonite and 24.73 and 1.14 for acid activated bentonite. This indicates that both adsorption systems were favorable and the acid activated bentonite had a higher adsorption capacity. 
Laila Al-Khatib et al. / American Journal of Environmental Science 8 (5) (2012) 510-522

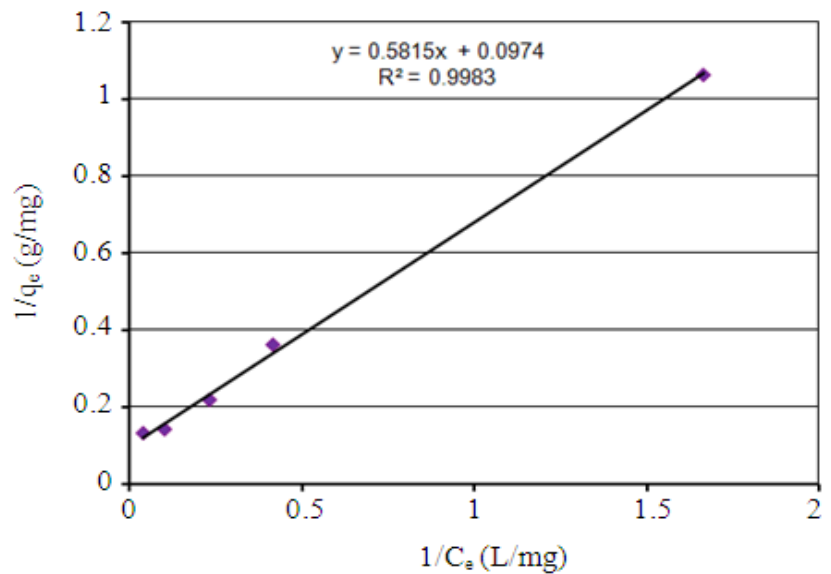

(A)

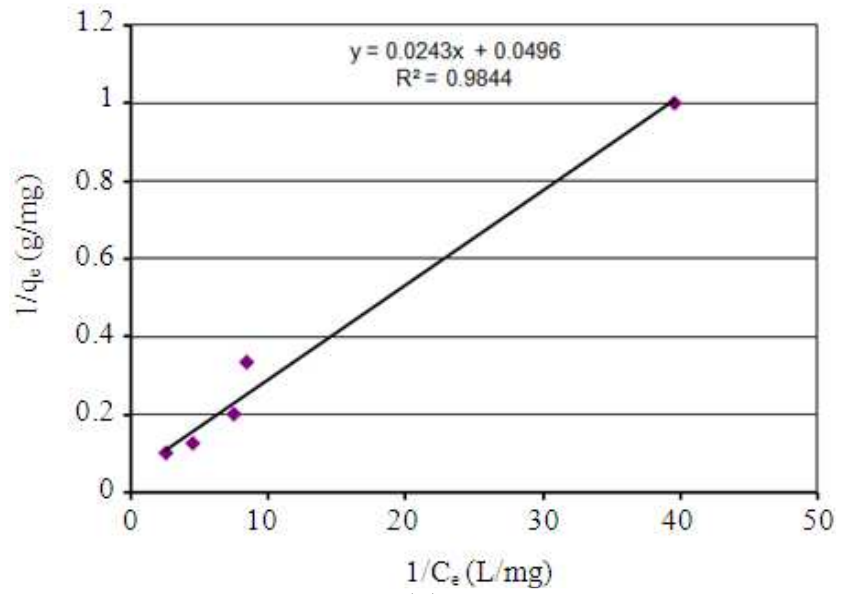

(B)

Fig. 8. Langmuir adsorption isotherm for $M B$ adsorbed on natural bentonite (A) and acid-activated bentonite (B) (initial concentration $=100 \mathrm{ppm}$, temperature $=20 \pm 2^{\circ} \mathrm{C}, \mathrm{pH}=9$ and dosage $=10 \mathrm{~g} \mathrm{~L}^{-1}$ )

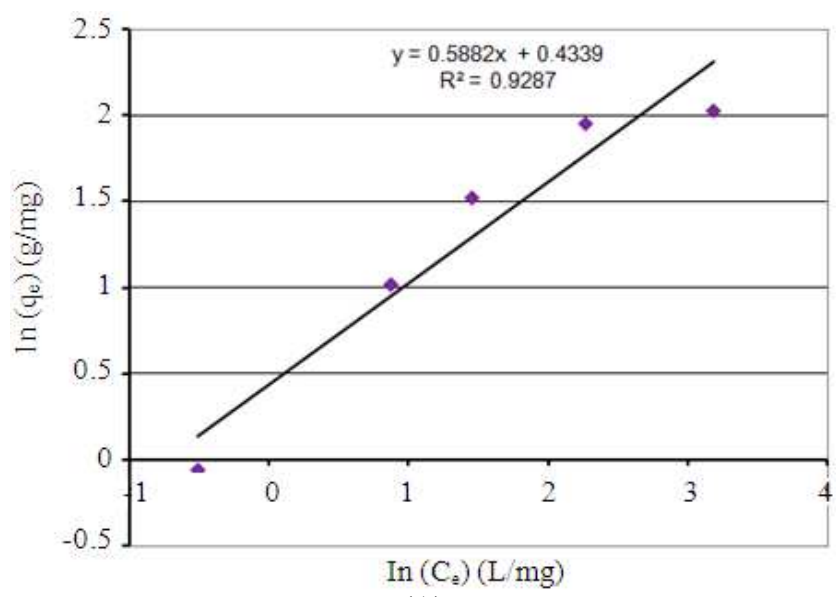

(A) 


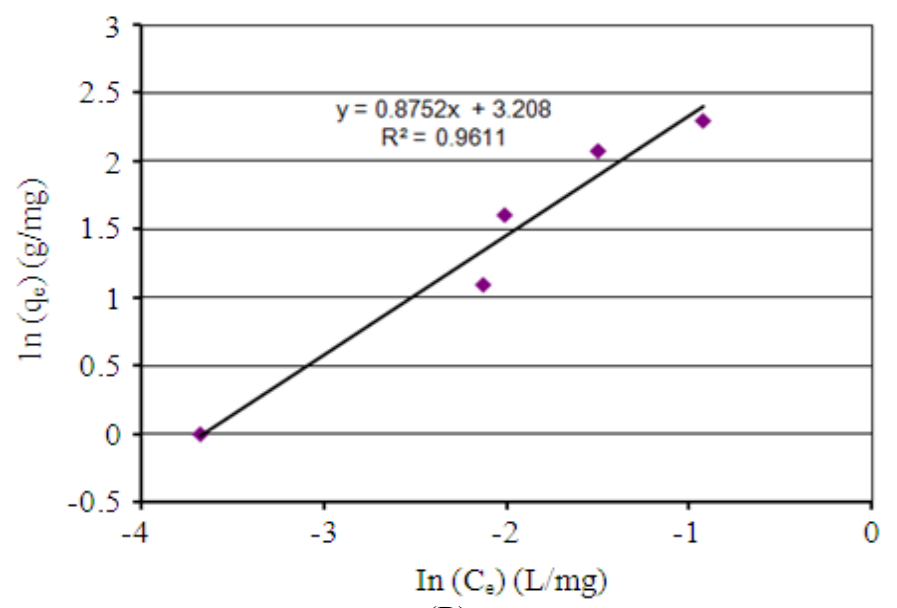

(B)

Fig. 9. Freundlich adsorption isotherm for $\mathrm{MB}$ adsorbed on natural bentonite (A) and acid-activated bentonite (B) (initial concentration $=100 \mathrm{ppm}$, temperature $=20 \pm 2^{\circ} \mathrm{C}, \mathrm{pH}=$ and dosage $=10 \mathrm{~g} \mathrm{~L}^{-1}$ )

Table 2. Isotherm models parameters for natural and acid-activated bentonite.

\begin{tabular}{llll}
\hline Isotherm model & Parameter & Natural bentonite & Acid-activated bentonite \\
\hline Langmuir & $\mathrm{q}_{\max }(\mathrm{mg} / \mathrm{g})$ & 10.27 & 20.16 \\
& $\mathrm{~K}_{\mathrm{L}}(\mathrm{L} / \mathrm{mg})$ & 0.167 & 2.041 \\
& $\mathrm{R}_{\mathrm{L}}$ & 0.056 & 0.005 \\
& $\mathrm{R}^{2}$ & 0.998 & 0.984 \\
Freundlich & $\mathrm{K}_{\mathrm{F}}(\mathrm{L} / \mathrm{mg})$ & 1.543 & 24.73 \\
& $\mathrm{n}$ & 1.700 & 1.143 \\
& $\mathrm{R}^{2}$ & 0.929 & 0.961 \\
\hline
\end{tabular}

Both the Langmuir and Freundlich isotherms parameters for the adsorption of MB onto natural and acidactivated bentonite and the correlation coefficients are summarized in Table 2. The correlation coefficients of the Langmuir model were higher than that of Freundlich model suggesting a more like monolayer adsorption process.

\section{DISCUSSION}

\subsection{Effect of Contact time and Initial (MB) Concentration on Adsorption}

The rate of adsorbed MB onto both natural and acid activated-bentonite was initially rapid and then it slowed down gradually until equilibrium was attained. It would be for that a large number of vacant surface sites were available for adsorption during the initial stage of the treatment time and after a lapse of time, less remaining vacant surface sites were available.

The amount of retained dye showed an increasing trend with the increase of initial dye concentration. Although the rate behavior of both bentonite and acid activated bentonite was similar, but it had been found that under identical conditions the acid activated bentonite presented higher adsorption capacity.

This increase in the adsorption capacity of activated bentonite may be attributed to many factors. $\mathrm{HCl}$ dissolved impurities such as calcite and leached cations from bentonite sheets. In addition, it replaced the exchangeable cations with hydrogen ions (Diaz and Santos, 2001). Furthermore, acid opened the edges of the platelets and produced a more porous structure which implied a greater surface area as illustrated by SEM images.

\subsection{Effect of pH on Adsorption}

The adsorption of $\mathrm{MB}$ dye onto natural bentonite increased with increasing solution $\mathrm{pH}$. This might be attributed to the surface charge of the natural bentonite. Bentonite is positively charged at low $\mathrm{pH}$ values and negatively charged at higher $\mathrm{pH}$ (Tahir and Rauf, 2006). Therefore the electrostatic interactions between the positively charged alkylamino groups in the dye molecule and the negatively charged adsorbent increased. As a result, the amount of dye molecules onto the natural bentonite increased at higher $\mathrm{pH}$ values. 
However, the adsorption of MB dye on acid activated bentonite was controlled by a $\mathrm{pH}$-independent adsorption mechanism as indicated in Fig. 4. It is believed that the adsorption mechanism occured partly by ion exchange releasing exchangeable cations in the interlayer and basal plane surfaces and partly via non-columbic interactions between an adsorbed cation and a neutralized site. Similar behavior was observed by Eren and Afsin (2008) and Turabik (2008).

\subsection{Effect of Temperature}

A slight increase in adsorption capacity of MB onto natural bentonite was observed with increasing temperature. This observation revealed that the adsorption process was slightly endothermic. This may be caused by the increased tendency of adsorbate ions mobility with temperature which slightly enhances the adsorption of MB from the solution into the clay (Hameed et al., 2007; Alkan and Dogan, 2003).

On the other hand, the adsorption capacity of $\mathrm{MB}$ onto acid activated bentonite has a negligible effect, suggesting the adsorption behavior is insensitive to the changes of temperature in this range. The weak influence of temperature for the adsorption of MB probably indicated the low activation energy in the predominantly ionic system (Hu et al., 2006).

\subsection{Effect of Adsorbent Dosage}

The increase in the adsorption efficiency of natural and acid activated bentonite by increasing the dosage can be explained by increasing surface area of the clay where the adsorption takes place.

However, when the dosage of acid- activated bentonite increased from 10 to $60 \mathrm{~g} \mathrm{~L}^{-1}$ the removal of $\mathrm{MB}$ is constant. This may be attributed to the attainment of equilibrium between adsorbate and adsorbent under the operating conditions. The adsorption process reached a saturation point after which no further MB adsorption took place.

\subsection{Adsorption Kinetics}

The regression coefficients obtained for pseudosecond order adsorption kinetic model for both bentonite were almost 1 , which indicated a good compliance of this model with experimental data. Consequently, the dye adsorption on natural and acid activated bentonite was assumed to be due to chemisorption.

With increasing initial dye concentration, the adsorption capacity increased for natural bentonite and acid activated bentonite. This indicated that dye removal content depends on the initial dye concentration when the adsorbent amount is constant.

\subsection{Adsorption Isotherms}

Regression analysis reveals that the Langmuir model fits the experimental data well with correlation factor higher than 0.98 for both adsorbents. This indicates that the adsorption mechanism of MB onto bentonite can be assumed as monolayer coverage and the adsorption is homogeneous, where the adsorption of each adsorbate molecule onto the surface has equal sorption activation energy.

The $\mathrm{R}_{\mathrm{L}}$ values were 0.056 for natural bentonite and 0.005 for acid activated bentonite as shown in Table 2 indicating that the adsorption of this dye on both adsorbents was a favorable process.

\section{CONCLUSION}

Bentonite deposits have been reported in different parts of Jordan. In the present study, bentonite clay was selected as a local, cheap and readily available adsorbent for the removal of $\mathrm{MB}$ from the aqueous solutions. Natural and acid activated bentonites were characterized using XRD, FTIR and SEM. Adsorption of the dye was studied by batch adsorption experiments.

Natural bentonite used is of montmorillonite nature as confirmed by the XRD analysis and chemical composition found in literature. FTIR and SEM analyses confirmed modification of bentonite treated with acid. This led to increase adsorption capacity of activated bentonite. It was observed that the percentage of dye removal was improved from $75.8 \%$ for natural bentonite to reach $99.6 \%$ for acid treated bentonite.

The results revealed that the adsorption of the dye increases with increasing the $\mathrm{pH}$ using natural bentonite. However, there was no effect of solution $\mathrm{pH}$ on the removal percentage of $\mathrm{MB}$ dye by acid activated bentonite.

In addition, they indicated a gradual increase in the percentage removal of $\mathrm{MB}$ dye with temperature for natural bentonite. However, no effect was observed when acid activated bentonite was used. An optimum dosage of both natural and acid activated bentonite is $10 \mathrm{~g} \mathrm{~L}^{-1}$.

The adsorption kinetic studies showed that the removal of $\mathrm{MB}$ is a rapid process and the adsorption process obeys the pseudo-second order model, indicating cationic dye has a very strong affinity on the bentonite surface. It was found that the experimental isotherm data can be fitted well to the Langmuir equilibrium isotherm model. 


\section{ACKNOWLEDGMENT}

Financial and in-kind support from King Abdullah II Fund for Development (KAFD) and King Abdullah II Design and Development Bureau (KADDB) is gratefully acknowledged. The authors would like to thank the Natural Resources Authority (NRA)-Jordan for supplying bentonite samples. Also, the authors would like to thank Engineers Jaber, Hawari, Dawoud and Zuriqat for their help in conducting some experiments.

\section{REFERENCES}

Alkan, M. and M. Dogan, 2003. Adsorption kinetics of victoria blue onto perlite. Fresen. Environ. Bull., 12: 418-425.

ALzaydien, A.S., 2009. Adsorption of methylene blue from aqueous solution onto a low-cost natural jordanian Tripoli. Am. J. Environ. Sci., 5: 197-208. DOI: 10.3844/ajessp.2009.197.208

Armagan, B., M. Turan and M.S. Elik, 2004. Equilibrium studies on the adsorption of reactive azo dyes into zeolite. Desalination, 170: 33-39. DOI: 10.1016/j.desal.2004.02.091

Chen, H. and J. Zhao, 2009. Adsorption study for removal of Congo red anionic dye using organoattapulgite. Adsorption, 15: 381-389. DOI: 10.1007/s10450-009-9155-z

Diaz, F.R.V. and P.D.S. Santos, 2001. Studies on the acid activation of Brazilian Smectitic clays. Química Nova, 24: 345-353. DOI: 10.1590/S010040422001000300011

Eren, E. and B. Afsin, 2008. Investigation of a basic dye adsorption from aqueous solution onto raw and pretreated bentonite surfaces. Dyes Pigments, 76: 220225. DOI: $10.1016 /$ j.dyepig.2006.08.019

Eren, E. and B. Afsin, 2009. Removal of basic dye using raw and acid activated bentonite samples. J. Hazard. Mater., 166: 830-835. PMID: 19188017

Farmer, V.C., 1971. The characterization of adsorption bonds in clays by infrared spectroscopy. Soil Sci., 112: 62-68.

Farmer, V.C., 1974. The layer silicates-the infrared spectra of minarlas.

Freundlich, H., 1906. Adsorption solution. Z. Phys. Chem., 57: 384-470.

Fu, Y. and T. Viraraghavan, 2000. Removal of a dye from an aqueous solution by the fungus Aspergillus niger. Water Qual. Res. J. Can., 35: 95-111.
Fu, Y. and T. Viraraghavan, 2001a. Fungal decolorization of dye wastewaters: A review. Bioresour. Technol., 79: 251-262. PMID: 11499579

Fu, Y. and T. Viraraghavan, 2001b. removal of C.I. acid blue 29 from an aqueous solution by Aspergillus niger. Am. Assoc. Text. Chem. Color. Rev., 1: 36-40.

Fu, Y. and T. Viraraghavan, 2002a. Removal of Congo Red from an aqueous solution by fungus Aspergillus niger. Adv. Environ. Res., 7: 239-247. DOI: 10.1016/S1093-0191(01)00123-X

Fu, Y. and T. Viraraghavan, 2002b. Dye biosorption sites in Aspergillus niger. Bioresour. Technol., 82: 139-145. PMID: 12003314

Gok, O., A.S. Ozcan and A. Ozcan, 2010. Adsorption behavior of a textile dye of Reactive Blue 19 from aqueous solutions onto modified bentonite. Applied Surf. Sci., 256: 5439-5443. DOI: 10.1016/j.apsusc.2009.12.134

Gupta, V.K. and Suhas, 2009. Application of low-cost adsorbents for dye removal--a review. J. Environ. Manage., 90: 2313-2342. PMID: 19264388

Hall, K.R., L.C. Eagleton, A. Acrivos and T. Vermeulen, 1966. Pore- and solid-diffusion kinetics in fixed-bed adsorption under constant-pattern conditions. Ind. Eng. Chem. Fundamen., 5: 212-223. DOI: 10.1021/i160018a011

Hameed, B.H., A.A. Ahmad and N. Aziz, 2007. Isotherms, kinetics and thermodynamics of acid dye adsorption on activated palm ash. Chem. Eng. J., 133: 195-203. DOI: 10.1016/j.cej.2007.01.032

Hameed, B.H., A.T. Din and A.L. Ahmad, 2001. Adsorption of methylene blue onto bamboo-based activated carbon: Kinetics and equilibrium studies. J. Hazard. Mater., 141: 819-825. PMID: 16956720

Hideomi, K., 1977. Clay for our future. Proceedings of the 11th International Clay Conference (ICC' 97), Ottawa, Canada, June 15-21.

Ho, Y.S. and G. McKay, 1998. Sorption of dye from aqueous solution by peat. Chem. Eng. J., 70: 115124. DOI: $10.1016 / \mathrm{S} 0923-0467(98) 00076-1$

Hu, H., S.Z. Qiao, F. Haghseresht, M.A. Wilson and G.Q. Lu, 2006. Adsorption study for removal of basic red dye using bentonite. Ind. Eng. Chem. Res., 45: 733-738. DOI: 10.1021/ie050889y

Juang, R.S., F.C. Wu and R.L. Tseng, 1997. The ability of activated clay for the adsorption of dyes from aqueous solutions. Environ. Technol., 18: 525-531. DOI: 10.1080/09593331808616568 
Khoury, H.N., 2002. Clays and Clay Minerals in Jordan. 1st Edn., University Jordan Publ., Amman, p: 116.

Komandel, P., D. Schmidt, J. Madejova and B. Cicel, 1990. Alteration of smectites by treatments with hydrochloric acid and sodium carbonate solutions. Applied Clay Sci., 5: 113-122. DOI: 10.1016/01691317(90)90017-J

Lagergren, S., 1898. About the theory of so-called adsorption of soluble substances. Kongliga Svenska Vetenskaps Academiens Handlingar, 24: 1-39.

Langmuir, I., 1918. The adsorption of gases on plane surfaces of glass, mica and platinum. J. Am. Chem. Soc., 40: 1361-1403. DOI: 10.1021/ja02242a004

Loeb, G.I. and M.E. Schrader, 1992. Modern Approaches to Wettability: Theory and Applications. 1st Edn., Springer, New York, ISBN10: 0306439859, pp: 484.

Olphen, H.V., 1977. An Introduction to Clay Colloid Chemistry. 2nd Edn., Wiley, New York, ISBN-10: 047101463X, pp: 318.

Ozcan, A.S. and A. Ozcan, 2004. Adsorption of acid dyes from aqueous solutions onto acid-activated bentonite. J. Colloid Interface Sci., 276: 39-46. PMID: 15219427

Poots, V.J.P., G. McKay and J.J. Healy, 1978. Removal of basic dye from effluent using wood as an adsorbent. J. Water. Pollut. Control Fed., 50: 926-935.

Srinivasan, A. and T. Viraraghavan, 2010. Decolorization of dye wastewaters by biosorbents: A review. J. Environ. Manage., 91: 1915-1929. PMID: 20627542
Tahir, S.S. and N. Rauf, 2006. Removal of a cationic dye from aqueous solutions by adsorption onto bentonite clay. Chemosphere, 63: 1842-1848. PMID: 16380152

Turabik, M., 2008. Adsorption of basic dyes from single and binary component systems onto bentonite: Simultaneous analysis of Basic Red 46 and Basic Yellow 28 by first order derivative spectrophotometric analysis method. J. Hazard. Mater., 158: 52-64. PMID: 18289779

Vlasova, M., G. Dominguez-Patino, N. Kakazey, M. Dominguez-Patino and D. Juarez-Romero et al., 2003. Structural-phase transformations in bentonite after acid treatment. Sci. Sinter., 35: 155-166.

Wang, S., H. Li and L. Xu, 2006. Application of zeolite MCM-22 for basic dye removal from wastewater. J. Colloid Interface Sci., 295: 71-78. PMID: 16143340

Waranusantigul, P., P. Pokethitiyook, M. Kruatrachue and E.S. Upatham, 2003, Kinetics of basic dye (methylene blue) biosorption by giant duckweed (Spirodela polyrrhiza). Environ. Pollut., 125: 385392. DOI: 10.1016/S0269-7491(03)00107-6

Wilson, M.J., 1994. Clay Mineralogy: Spectroscopic and Chemical Determinative Methods. 1st Edn., Chapman and Hall, London, ISBN-10: 0412533804, pp: 367. 